\title{
Research Forum
}

\section{Listening Comprehension in Middle-Aged Adults}

\author{
Mitchell S. Sommers ${ }^{a}$
}

\begin{abstract}
Purpose: The purpose of this summary is to examine changes in listening comprehension across the adult lifespan and to identify factors associated with individual differences in listening comprehension.

Method: In this article, the author reports on both cross-sectional and longitudinal changes in listening comprehension.
\end{abstract}

\begin{abstract}
Conclusions: Despite significant declines in both sensory and cognitive abilities, listening comprehension remains relatively unchanged in middle-aged listeners (between the ages of 40 and 60 years) compared with young listeners. These results are discussed with respect to possible compensatory factors that maintain listening comprehension despite impaired hearing and reduced cognitive capacities.
\end{abstract}

$\mathrm{M}$ ost prior research on aging and speech perception has focused principally on how identification of relatively short linguistic segments changes across the lifespan, and whether those changes are similar for different types of materials (Committee on Hearing and Bioacoustics, 1988). This summary focuses on investigating the pattern of age-related changes in understanding extended passages of speech, rather than identification of isolated words and sentences across the adult lifespan. The current report summarizes my results using both cross-sectional and longitudinal approaches, with a particular emphasis on middle-aged adults between the ages of 40 and 60 years. The focus on middle-aged adults will serve to establish whether any observed changes in listening comprehension parallel the well-documented declines in both sensory and cognitive abilities in this age group (Greenwood, Espeseth, Lin, Reinvang, \& Parasuraman, 2014; Morrell, Gordon-Salant, Pearson, Brant, \& Fozard, 1996).

On one hand, the expectation might be systematic and progressive declines in listening comprehension across the adult lifespan that parallel age-related declines in auditory thresholds (Morrell et al., 1996) and cognitive abilities (Greenwood et al., 2014). For example, Schneider, Daneman, Murphy, and See (2000) found that when audibility was equated across groups of younger and older adults, they performed similarly on measures of listening comprehension. In contrast, when audibility was allowed to differ

\footnotetext{
${ }^{\text {a}}$ Washington University in St. Louis, MO

Correspondence to Mitchell Sommers: msommers@wustl.edu

Editor and Associate Editor: Larry Humes

Received October 16, 2014

Revision received February 2, 2015

Accepted February 5, 2015

DOI: 10.1044/2015_AJA-14-0060
}

across the two age groups, older listeners exhibited significant reductions in listening comprehension. These results suggest that even small declines in auditory sensitivity can impair the ability to understand spoken passages. Of particular importance to investigations with middle-aged adults, age-related hearing loss can begin as early as the third decade of life (Morrell et al., 1996). Thus, the findings from Schneider et al. (2000) would predict relatively similar functions relating hearing loss and listening comprehension across the adult lifespan.

Listening comprehension may remain relatively unchanged in middle-aged listeners because age differences in word identification are significantly attenuated for meaningful contexts and spoken passages provide exactly this type of semantically rich environment. Furthermore, listening comprehension does not require accurate identification of each word. Instead, understanding spoken passages requires individuals to obtain the gist or general meaning of the passage, even if they can't identify each of the individual words.

To my knowledge, only one previous investigation (Kaufman \& Horn, 1996) has examined changes in the ability to understand extended spoken passages in middle-aged listeners. Kaufman and Horn (1996) tested a normative sample of adults aged between 17 and 94 years on the Auditory Comprehension subtest of the Kaufman Adolescent and Adult Intelligence Test (Kaufman \& Kaufman, 1993). Participants heard recordings of a news story and then answered both detail-specific and inferential questions about the content. Performance declined from the youngest age group through middle adulthood (until about age 55 years), followed by an accelerated decline during late adulthood. An unfortunate limitation of the Kaufman and Horn (1996) 
data is that, because auditory acuity was not assessed, it is not possible to determine the extent to which changes in listening comprehension paralleled any changes in hearing loss.

In my cross-sectional research, I administered a battery of sensory and cognitive measures as well as three tests of listening comprehension (for details of the specific comprehension measures, please see Sommers et al., 2011) to adults between the ages of 20 and 90 years. Sensory measures included assessment of hearing thresholds and word identification in noise. The evaluation of cognitive abilities included measures of working memory, processing speed, and executive functions. The listening comprehension tests presented individuals with passages ranging in length from 2 to $5 \mathrm{~min}$ and examined individuals' ability to answer comprehension questions following each passage. Although overall performance differed across the three comprehension measures, the pattern of results for the instruments was similar and the mean performance across seven decades is displayed in Figure 1. Listening comprehension remained relatively unchanged from age 20 to 70 years and then declined $2 \%-3 \%$ per year after approximately age 75 years. Individual differences analysis for the older adults (over age 70 years) indicated that reductions in absolute sensitivity and working memory were the two biggest contributors to reduced listening comprehension.

As a follow-up to my cross-sectional studies, individuals returned between 4 and 5 years $(M=4.38, S D=0.5)$ after their initial testing to examine longitudinal changes in working memory, auditory thresholds, and listening comprehension. Forty-one of the original 120 participants between the ages of 40 and 60 years returned for the follow-up

Figure 1. Mean of three measures of comprehension as a function of age. Performance is expressed in standardized units to accommodate different scales across the three measures. The solid line indicates a piecewise linear fit, and the dashed line represents an exponential fit to the entire data set. For the middle-aged adults in the current study, the piecewise linear function provided a nonsignificantly better fit than the exponential function. LISN = Lectures, Interviews, and Spoken Narratives (Tye-Murray et al., 2008); SAT = Scholastic Aptitude Test; BCC = Brown-Carlsen-Carstens Listening Comprehension Test (Brown et al., 1995).

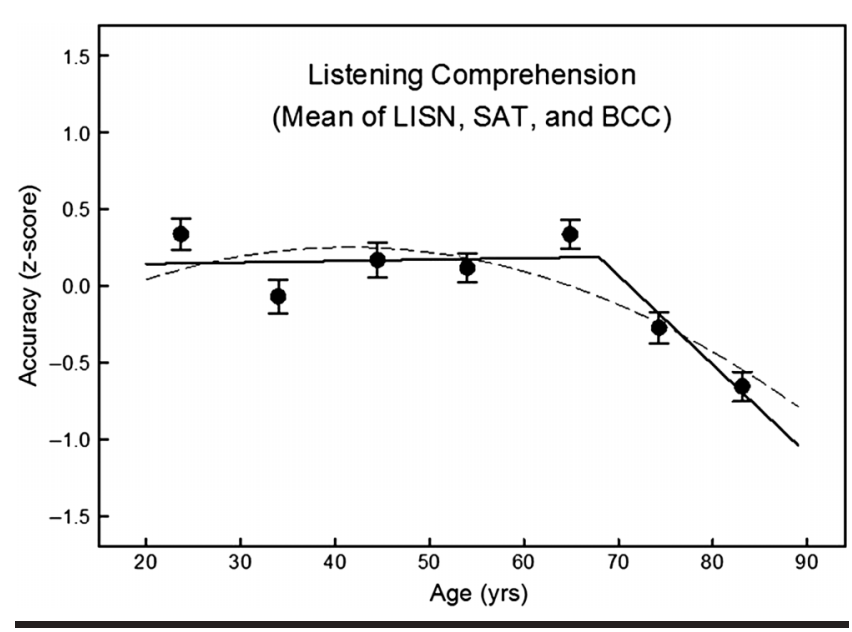

assessments. Returners and nonreturners did not differ on any of the measures obtained during the initial testing. As might be expected, the majority of individuals had greater hearing loss at the Time 2 follow-up, with average changes of approximately 8-10 dB across frequencies from $250 \mathrm{~Hz}$ to $4000 \mathrm{~Hz}$. Similar results were obtained for measures of speech identification in noise; participants exhibited an average of $8.2 \%(S D=7.1)$ reduction in spoken word identification from Time 1 to Time 2 . With the exception of one measure of working memory (forward digit span), the majority of the older participants also exhibited reductions in working memory span during the approximate 5-year interval between testing. Despite the significant declines in both sensory and cognitive abilities, the majority of middleaged participants surprisingly exhibited a (nonsignificant) trend toward improved comprehension at Time 2 compared to Time 1. Mean improvement across the two testing times was approximately 5.2\% $(S D=4.6)$.

If the performance of the young adults is a baseline measure of listening comprehension for individuals with little or no decline in sensory or cognitive abilities, one of the principal questions raised by the results of the current study is why listening comprehension remains relatively unchanged for middle-aged adults, despite mild-to-moderate hearing loss and reduced cognitive abilities. I propose two, not mutually exclusive, explanations for the well-preserved listening comprehension of middle-aged adults. First, the presbycusic hearing loss in middle-aged listeners was confined largely to frequencies above $2000 \mathrm{~Hz}$, and lower frequencies are more important for the intelligibility of connected discourse compared with either nonsense syllables or isolated words (Studebaker, Pavlovic, \& Sherbecoe, 1987). Hornsby and Ricketts (2006) note that speech information is redundant across frequencies and many individuals with poor high-frequency hearing are able to make good use of low-frequency information, especially in quiet (Ching, Dillon, \& Byrne, 1998). In the present study, all of the material was presented in quiet. Thus, middle-aged adults may use their relatively well-preserved low-frequency hearing to compensate for any high-frequency hearing losses.

A second possible explanation for the maintenance of listening comprehension through middle age is that the spoken materials used in the current study provide a rich semantic context that can compensate for age-related changes in both auditory sensitivity and word recognition (Hutchinson, 1989; Nittrouer \& Boothroyd, 1990; Sommers \& Danielson, 1999). Previous studies have found that age differences in identifying both individual words and entire sentences can be significantly reduced by introducing a meaningful semantic context. Sommers and Danielson (1999), for example, found differences between older and younger adults of approximately $25 \%-30 \%$ for identifying sentencefinal words in low-predictability contexts (e.g., She was thinking about the shark), but differences of only $5 \%-10 \%$ when those same words were presented in high-predictability contexts (e.g., I was attacked by a shark). As hearing loss occurs gradually over the adult lifespan (Morrell et al., 1996), older adults have increased opportunities to learn to 
use semantic context in order to compensate for age-related sensory declines and thereby exhibit relatively well-preserved understanding of meaningful passages.

One potential limitation of the current work is that the measures of comprehension used in the current investigation were not sufficiently sensitive to detect subtle changes in the quality of comprehension. For example, there is evidence (Dixon, Simon, Nowak, \& Hultsch, 1982) that gist recall declines in middle-aged adults, making the longitudinally preserved listening comprehension abilities of this group somewhat surprising. In this regard, it is important to note that listening comprehension requires a number of sensory and cognitive primitives, including gist recall that may be differentially affected by aging. It will therefore be important for future research to develop measures that assess both overall comprehension as well as its specific components.

From a broader perspective, the picture that emerges from studies of listening comprehension is that it is among a highly select group of abilities that show relative stability across most of the adult lifespan. The critical challenge for future studies of listening comprehension will be twofold. First, it will be essential to identify the sensory and cognitive abilities mediating listening comprehension. Second, investigations aimed at identifying and training potential compensatory mechanisms used to maintain listening comprehension may serve to preserve individuals' ability to understand spoken message well into middle age.

\section{References}

Brown, J. I., Carlsen, G. R., \& Carstens, L. (1995). BrownCarlsen-Carstens Listening Comprehension Test. New York, NY: Harcourt.

Ching, T. Y. C., Dillon, H., \& Byrne, D. (1998). Speech recognition of hearing-impaired listeners: Predictions from audibility and the limited role of high-frequency amplification. The Journal of the Acoustical Society of America, 103, 1128-1140.

Committee on Hearing and Bioacoustics (CHABA), Working Group on Speech Understanding and Aging. (1988). Speech understanding and aging. The Journal of the Acoustical Society of America, 83, 859-895.

Dixon, R. A., Simon, E. W., Nowak, C. A., \& Hultsch, D. F. (1982). Text recall in adulthood as a function of level of information, input modality, and delay interval. Journal of Gerontology, 37, 358-364.

Greenwood, P. M., Espeseth, T., Lin, M. K., Reinvang, I., \& Parasuraman, R. (2014). Longitudinal change in working memory as a function of APOE genotype in midlife and old age. Scandinavian Journal of Psychology, 55, 268-277.

Hornsby, B. W., \& Ricketts, T. A. (2006). The effects of hearing loss on the contribution of high- and low-frequency speech information to speech understanding. II. Sloping hearing loss. The Journal of the Acoustical Society of America, 119, 1752-1763.

Hutchinson, K. M. (1989). Influence of sentence context on speech perception in young and older adults. Journal of Gerontology, 44, 36- 44 .

Kaufman, A. S., \& Horn, J. L. (1996). Age changes on tests of fluid and crystallized ability for women and men on the Kaufman Adolescent and Adult Intelligence Test (KAIT) at ages 17-94 years. Archives of Clinical Neuropsychology, 11, 97-121.

Kaufman, A. S., \& Kaufman, N. L. (1993). Kaufman Adolescent and Adult Intelligence Test. Sydney, New South Wales, Australia: Pearson.

Morrell, C. H., Gordon-Salant, S., Pearson, J. D., Brant, L. J., \& Fozard, J. L. (1996). Age- and gender-specific reference ranges for hearing level and longitudinal changes in hearing level. The Journal of the Acoustical Society of America, 100, 1949-1967.

Nittrouer, S., \& Boothroyd, A. (1990). Context effects in phoneme and word recognition by young children and older adults. The Journal of the Acoustical Society of America, 87, 2705-2715.

Schneider, B. A., Daneman, M., Murphy, D. R., \& See, S. K. (2000). Listening to discourse in distracting settings: The effects of aging. Psychology and Aging, 15, 110-125.

Sommers, M. S., \& Danielson, S. M. (1999). Inhibitory processes and spoken word recognition in young and older adults: The interaction of lexical competition and semantic context. Psychology and Aging, 14, 458-472.

Sommers, M. S., Hale, S., Myerson, J., Rose, N., Tye-Murray, N., \& Spehar, B. (2011). Listening comprehension across the adult lifespan. Ear and Hearing, 32, 775-781.

Studebaker, G. A., Pavlovic, C. V., \& Sherbecoe, R. L. (1987). A frequency importance function for continuous discourse. The Journal of the Acoustical Society of America, 81, 1130-1138.

Tye-Murray, N., Sommers, M., Spehar, B., Myerson, J., Hale, S., \& Rose, N. S. (2008). Auditory-visual discourse comprehension by older and young adults in favorable and unfavorable conditions. International Journal of Audiology, 47(Suppl. 2), S31-S37. 